\title{
Research on Mining-Induced Stress Distribution of Extrathick Coal Seams Based on Electromagnetic Wave CT Technology
}

\author{
Tuan He $\mathbb{D}^{1,2,3}$ Guodong Li $\mathbb{D}^{1},{ }^{2}$ Feng Luo, ${ }^{2}$ and Xueqing Li $\mathbb{D}^{2}$ \\ ${ }^{1}$ China Coal Research Institute, Beijing, China \\ ${ }^{2}$ Hebei University of Engineering, Handa, Hebei, China \\ ${ }^{3}$ Xi'an University of Science and Technology, State Key Laboratory of Coal Resources, Western China, Xi'an, China \\ Correspondence should be addressed to Guodong Li; gd.li@cqu.edu.cn
}

Received 19 October 2021; Accepted 24 January 2022; Published 21 February 2022

Academic Editor: Minghui Li

Copyright ( $\odot 2022$ Tuan He et al. This is an open access article distributed under the Creative Commons Attribution License, which permits unrestricted use, distribution, and reproduction in any medium, provided the original work is properly cited.

\begin{abstract}
Fully mechanized caving mining in extrathick coal seams is currently the most efficient mining method. To figure out the mininginduced stress in extrathick coal seams which is significantly different from the normal ones is essential for mining safety. This research is based on the No. 3106 working face of Lu-Zi-Gou coal mine in China, which extracts extrathick coal seams by using the comprehensive mechanized top-coal caving method. According to the elastoplastic theory, a multiforce superposition mininginduced stress model is constructed in this research. In this model, the mining-induced stress is generated by the side coal seam of the stope, including the load formed by the broken roof blocks in the caving zone, the unbroken rock layers in the side of the goaf, and the rock layers in the bending zone. To verify the model, electromagnetic wave CT detection and borehole endoscopy are used to test the coal's electromagnetic wave attenuation and internal joints. The results indicate that the mining of extrathick coal seams forms internal and external stress fields in the side coal seams of the stope. As the depth increases, the mining-induced stress first increases and then decreases within the two areas. According to the above conclusions, the width of coal pillars and the location of roadways between adjacent working faces can be reasonably determined.
\end{abstract}

\section{Introduction}

In Northwest China, there are vast reserves of coal resources. Some coal seams' thickness exceeds $20 \mathrm{~m}$, which is an extrathick coal seam [1]. The extrathick coal seam provides geological conditions for maximizing coal mining efficiency. The mining of extrathick coal seams is an efficient way of extracting coal resources. In the past ten years, mines excavating extrathick coal seams have occupied an increasingly important position in China's energy system, such as Tashan and Tong-Qi coal mines in Shanxi, Huating coal mine in Gansu, and Bu-Lian-Gou coal mine $[2,3]$. A working face of the Bu-Lian-Ta coal mine in Inner Mongolia for mining extrathick coal seams has set a world record of 14 million tons of raw coal output per year [4]. The length of the working face in the extrathick coal seam is between $150 \mathrm{~m}$ and $300 \mathrm{~m}$, and the fully mechanized top-coal caving mining method is mostly utilized [5]. However, the mining of extrathick coal seams will produce oversized goaf. In addition, the range of the influence of mining-induced stress, the maximum pressure, and the damage depth of the surrounding rock is much more extensive than that in regular coal seam mining [6]. Under the influence of mining-induced stress, the surrounding rock in the roadway, working face, chamber, and other areas deform massively which is hard to control. The above hazards seriously restrict the safe and efficient production of extrathick coal seams.

Due to the lack of long-term, stable, and effective technology and equipment for monitoring mining-induced stress and surrounding rock damage [7], physical simulation, numerical simulation, and theoretical modeling are often used to study the distribution and evolution of mininginduced stress under the condition of comprehensive topcoal caving mining in the extrathick coal seam [8]. The 
research results show that the mining-induced stress forms internal and external stress fields in the "caved zone" and "bending subsidence zone," which bear the load generated by the overlying strata and the broken roof block in the goaf, respectively. The "internal" stress field is the primary source of mining-induced stress $[9,10]$. It may also increase the ineffectiveness of supports and unpredictability at the goaf edges which may result in risky caving in-bye in the topcaving mining [11]. Kumar et al. and Mandal et al. conducted field research on Zero coal seams in Kajora area of which the thickness was more than $7.0 \mathrm{~m}$. It showed that the mining of extrathick coal seams caused different surface subsidence and crack distribution [12, 13]. He et al. [14], Zhao et al. [15], and Zhu et al. [16] studied the internal and external stress fields under the mining of extrathick coal seams. They obtained the distribution and evolution of highstress concentration in the internal stress field in the mining plane.

The cross-hole electromagnetic wave CT detection is one of the on-site geophysical testing methods which can be used to monitor mining-induced stress. The electromagnetic waves are generated and received by the devices in the two boreholes, and the properties of the rock strata are determined based on the attenuation of the electromagnetic wave $[17,18]$. The electromagnetic wave CT technology has been widely used because it has advantages of high detection accuracy, fast speed, and convenient equipment operation, including exploration and examination of the coal mine geological structure, distribution of groundwater, damage area of the surrounding rock, stability of the intersection coal pillar, and other geological and disaster information $[19,20]$.

At present, the research of the distribution and evolution of mining-induced stress needs to be further studied under the condition of fully mechanized top-coal caving in the extrathick coal seam. Therefore, this research explores the use of cross-hole electromagnetic wave CT detection to examine the mining-induced stress of extrathick coal seams. In addition, in the process of fully mechanized caving mining in extrathick coal seams, the evolution process of mining-induced stress is analyzed.

\section{Distribution of Mining-Induced Stress in the Extrathick Coal Seam}

2.1. Geology and Mining Conditions. The Lu-Zi-Gou coal mine is located in Shanxi Province, China, with a coal output of $3 \mathrm{Mt} / \mathrm{a}$. No. 3106 working face is one of the prominent working faces of this mine. It excavates a composite coal seam which included three coal seams, Nos. 2\#, 3\#, and 5\#. The average thickness of the coal seam in this area is $25 \mathrm{~m}$, the maximum value is $29 \mathrm{~m}$, the inclination angle is $3^{\circ}$, and the buried depth is $350 \mathrm{~m}$. The mining height is $25 \mathrm{~m}$. No. 3106 working face adopts the comprehensive top-coal caving method, with a dip length of $150 \mathrm{~m}$ and the strike length of $1200 \mathrm{~m}$. Hydraulic fracturing and blasting are used to weaken the top coal above the hydraulic support to improve the recovery rate of coal resources. The width of the mining roadway is $4 \mathrm{~m}$. The adjacent working face of No. 3106 is No.

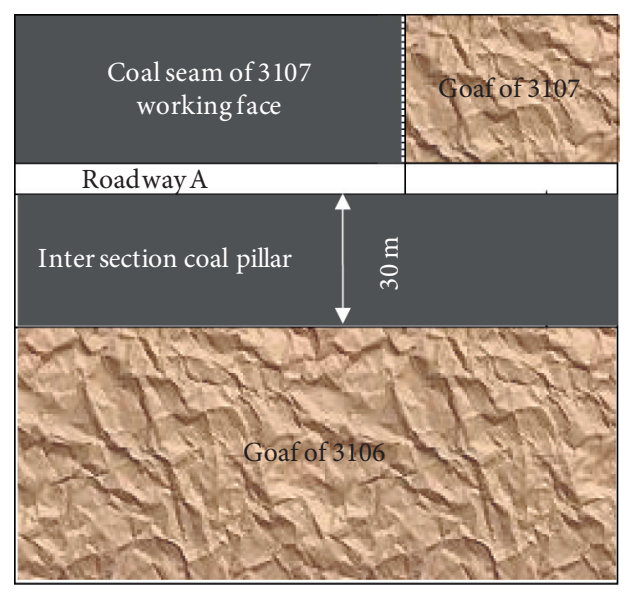

FIgURE 1: Layout of the working face.

3107. There is a $30 \mathrm{~m}$-wide coal pillar between these two working faces (Figure 1).

2.2. Mechanical Modeling. After the extrathick coal seam is mined, the breaking and moving boundary of the roof can be approximated as a straight line obliquely crossing the coal seam with angles $\alpha$ and $\beta$ (Figure 2). In the vertical direction, according to rock strata's movement, deformation, and fracture characteristics above the goaf, it can be divided into the caved, fracture, and bending zones [21]. The mininginduced stress formed at point $M$ in the side coal seam of the stope is caused by the superposition of multiple forces. In the caved zone, the broken roof in the goaf attaches and applies a load on the unbroken rock strata, which are at the side of the stope. The lateral intact rock strata of the stope deflect under the action of its weight. The two ends of the curved zone are, respectively, located above the lateral coal body in the goaf and are firmly supported. The broken roof in the goaf, the unbroken roof on the side of the goaf, and the rock strata in the bending zone together form the mining-induced stress. The stress at point $M$ can be analyzed based on stress superposition. According to the above analysis, a multiforce superposition mining-induced stress model (MSMS model) can be established. The MSMS model is based on elastic beams, and the force analysis is based on theoretical mechanics.

For point $M$ in the side coal seam of the stope, the mining-induced stress is composed of the weight stress of the overlying strata, the additional stress which is generated by the broken roof in the goaf, and the stress which is produced by the bending zone:

$$
\sigma=\sigma_{\gamma}+\sigma_{1}+\sigma_{2} .
$$

According to the horizontal location of point $M$ in the coal seam, $\sigma_{\gamma}$ can be calculated by the following equation:

$$
\sigma_{\gamma}= \begin{cases}\gamma\left(H_{1}+H_{2}\right), & {\left[0,\left(H_{1}+H_{2}\right) \cot \alpha\right],} \\ \gamma \chi \tan \alpha, & {\left[\left(H_{1}+H_{2}\right) \cot \alpha, H \cot \alpha\right],} \\ \gamma H, & {[H \cot \alpha,+\infty] .}\end{cases}
$$




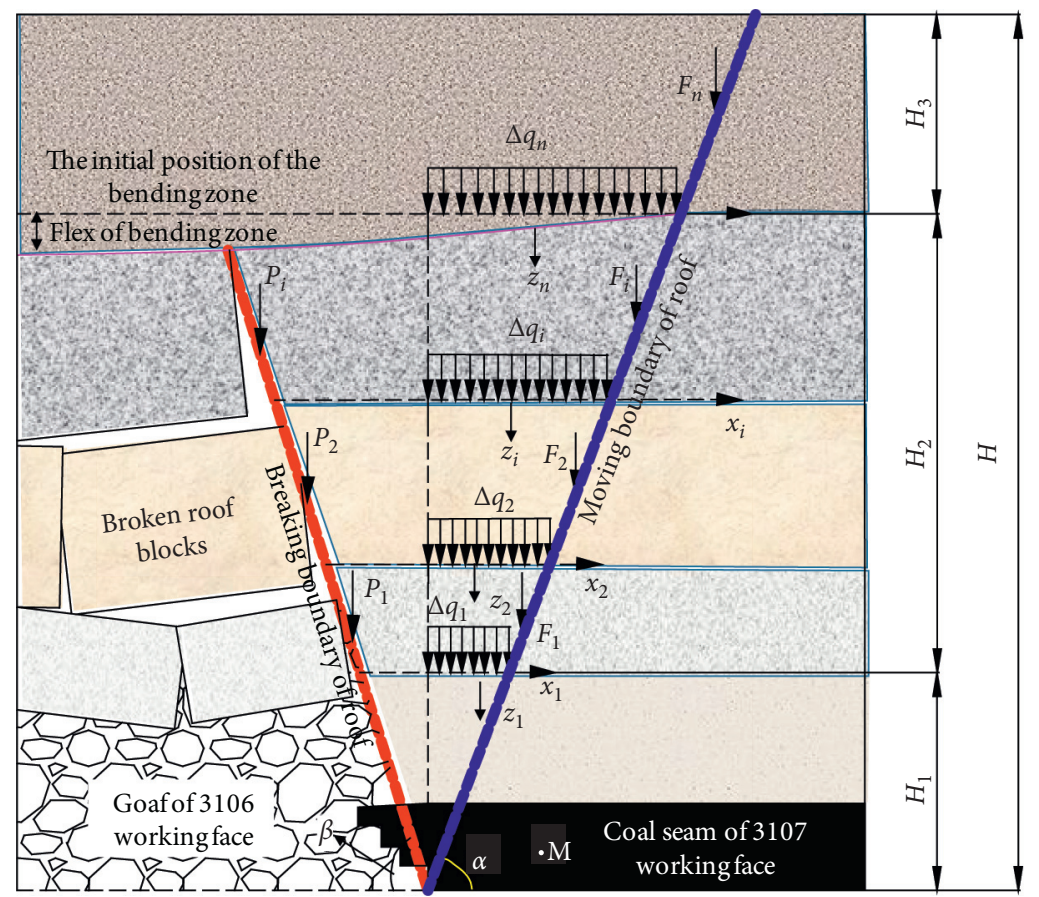

Figure 2: Mechanical model of the stope.

The load $\triangle q_{i}$ generated by the broken roof in the side of the goaf can be calculated through the following formula $[10,11]$ :

$$
\Delta q_{i}=\frac{\gamma h_{i} \cot \beta}{\cot \alpha}+\frac{p_{i}}{H_{i} \cot \beta} .
$$

The stress generated by $\Delta q_{i}$ at point $M$ is $\sigma_{F_{i} / M}$, and the mechanical model to calculate $\sigma_{F_{i} / M}$ is shown in Figure 3 .

In Figure 3, $\mathrm{d} \Delta q_{i}=\Delta q_{i} \mathrm{~d} x, d x=r d \theta / \cos \theta$, and $d q_{i}$ can be calculated through the following formula:

$$
d q_{i}=\frac{\Delta q_{i} \times r \times d \theta}{\cos \theta} .
$$

The vertical stress component generated by $d q_{i}$ at point $M$ is

$$
d q_{i / M}=\frac{2 d q_{i}}{\pi} \times \frac{\cos ^{3} \theta}{r} .
$$

After calculus and superposition calculation, the following formula can be obtained:

$$
\sigma_{q i / M}=\frac{\Delta q_{i}}{\pi} \times\left(\theta_{1}-\theta_{2}+0.5 \sin 2 \theta_{1}-0.5 \sin 2 \theta_{2}\right) .
$$

By superimposing the stress which is generated by all lateral unbroken rock layers, the calculation equation of $\Delta \sigma_{1}$ is

$$
\sigma_{1}=\sum_{i=1}^{n} \sigma_{q_{i} / M} .
$$

The ends of the rock stratum in the bending zone are fixed. Near the fulcrum, the loads generated by deflection are $F_{1}, F_{2}, \ldots, F_{i}, \ldots, F_{n}$ as shown in the following formula:

$$
F_{i}=\left(H_{i} \cot \alpha+\frac{L}{2}\right) h_{i} \gamma g .
$$

The stress $\sigma_{\mathrm{F}_{i} / \mathrm{M}}$ generated by $F_{i}$ at point $M$ can be calculated as follows:

$$
\sigma_{F_{i} / M}=-\frac{2 F_{i}}{\pi} \cdot \frac{x^{3}}{\left(x^{2}+y^{2}\right)^{2}} .
$$

The calculation equation of $\sigma_{2}$ can be obtained by accumulating the stress generated by the rock strata in the bending zone:

$$
\sigma_{2}=\sum_{i=1}^{n} \sigma_{F_{i} / M}
$$

Bringing equations (5) and (8) into equation (1), the mininginduced stress calculation formula at point $M$ can be obtained:

$$
\sigma=\sigma_{\gamma}+\sum_{i=1}^{n} \sigma_{q_{i} / M}+\sum_{i=1}^{n} \sigma_{F_{i} / M} .
$$

2.3. Mining-Induced Stress Distribution. Based on the geology and mining situations of the Lu-Zi-Gou coal mine, the values of the parameters in the MSMS model can be obtained (Table 1).

By bringing the values in Table 1 into the MSMS model, the distribution curve of mining-induced stress in the coal seam can be calculated (Figure 4). It shows that the range of mining impact area reaches $60 \mathrm{~m}$. Moreover, there are two stress fields within this area: internal stress field (ISF) and external stress field (ESF). In the two fields, as the buried depth increases, the stress first rises and then decreases. The width of the internal stress field is 


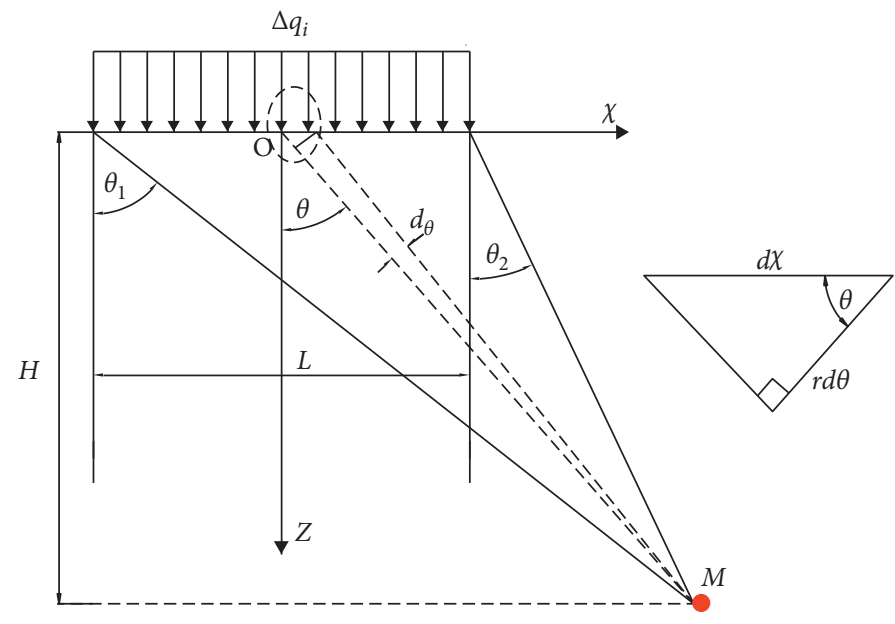

Figure 3: The calculation model of $\sigma_{F_{i} / M}$.

TABLE 1: Values of parameters of the MSMS model based on the Lu-Zi-Gou coal mine.

\begin{tabular}{|c|c|c|c|c|c|c|}
\hline Parameter & $h$ & $H(\mathrm{~m})$ & $\gamma$ of coal & $\gamma$ of the rock & $\alpha$ & $\beta$ \\
\hline Value & 25 & 350 & $14 \times 10^{3} \mathrm{~N} / \mathrm{m}^{3}$ & $25 \times 10^{3} \mathrm{~N} / \mathrm{m}^{3}$ & $81^{\circ}$ & $75^{\circ}$ \\
\hline
\end{tabular}

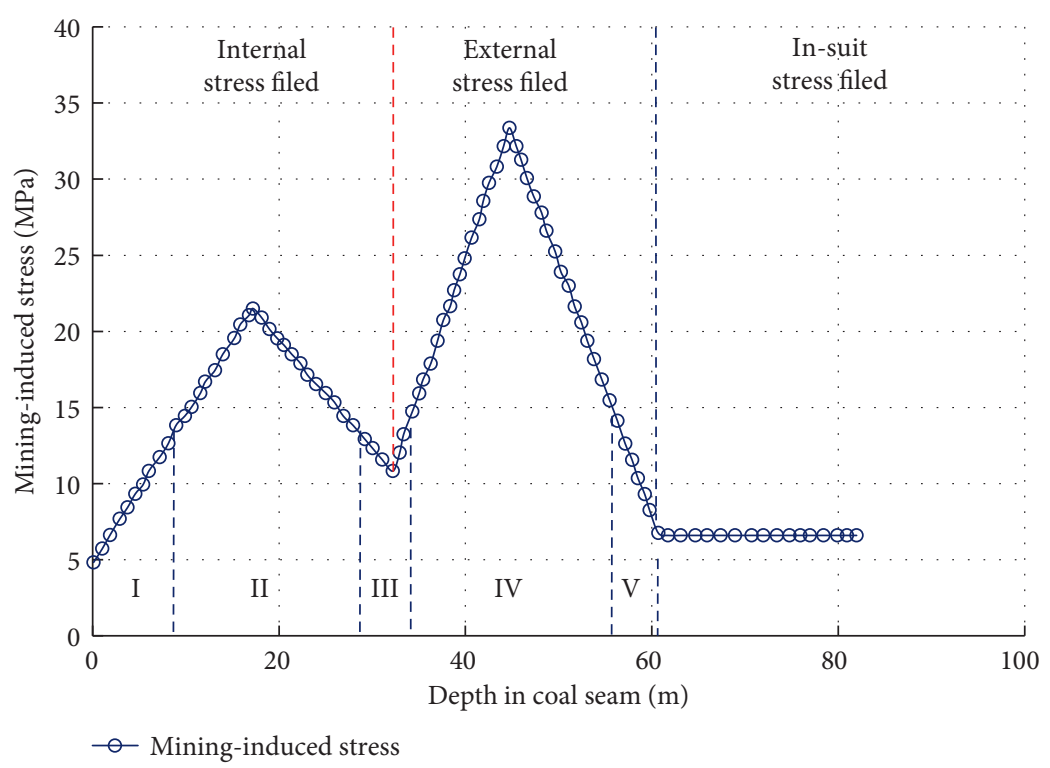

Figure 4: The distribution of mining-induced stress in the coal seam.

$0-32 \mathrm{~m}$, and the maximum value is $23 \mathrm{MPa}$ which is $16 \mathrm{~m}$ away from the goaf. The range of the external stress field is $32-60 \mathrm{~m}$ with the peak value of $34 \mathrm{MPa}$, which is $44 \mathrm{~m}$ to the goaf.

According to the distribution of mining-induced stress, the internal and external stress fields of fully mechanized top-coal caving mining in extrathick coal seams can be divided into five areas. From the edge of the goaf to the inside of the coal seam, they are the low-stress area in ISF (I), the high-stress area in ISF (II), low-stress area at the junction (III), the high-stress area in ESF (IV), and the low-stress area in ESF (V). The distribution of mining-induced stress and regional division provide a basis for reasonably determining the location of adjacent roadways and the width of coal pillars. Area III is the best scope for the adjacent working faces' mining roadways to minimize coal loss. Therefore, the width of coal pillars between No. 3106 and No. 3107 working faces is $30 \mathrm{~m}$.

\section{Field Test}

3.1. Principle of Electromagnetic Wave CT Detection. The electromagnetic wave CT detection technology is based on the geometric ray theory. The electrical difference between the detection target and the surrounding medium is used to calculate the propagation characteristics of electromagnetic waves between the two boreholes and the absorption by the medium. Furthermore, the position, shape, and size of the 
target body, the degree of damage of the rock mass, and the difference in stress appearance can be further determined. As the penetration depth increases, the electromagnetic wave continues to attenuate. The reasons that affect the attenuation include the diffusion of electromagnetic waves, the reflection and scattering on the media interface with different electrical properties, and the absorption of coal and rock media. The electromagnetic wave attenuation coefficient is used to describe this phenomenon quantitatively. According to Maxwell's equation, $\beta_{s}$ can be calculated [22]:

$$
\beta_{s}=\omega \sqrt{\mu \varepsilon} \sqrt{\frac{1}{2}\left[\sqrt{1+\left(\frac{K}{\omega \varepsilon}\right)^{2}}-1\right]} .
$$

The following formula can calculate the electromagnetic field strength in the medium:

$$
E=E_{0}^{\prime} \frac{e^{-\beta r}}{r} f(\theta),
$$

in which $E$ is the field strength of the receiving point, $\mathrm{V} / \mathrm{m}$; $E_{0}^{\prime}$ is the initial radiation constant, $\mathrm{V} / \mathrm{m} ; \beta$ is the absorption coefficient, which is the absorption value of electromagnetic wave per unit distance in the medium, $\mathrm{dB} / \mathrm{m} ; f(\theta)$ is the direction factor function of the electromagnetic wave generating and receiving probe; $r$ is the distance between the detection holes, $m$.

According to the change of $\beta_{s}$ in the test area, particular analysis software is used in the electromagnetic wave CT detection to invert the distribution of the electromagnetic wave on the fluoroscopic section. Due to differences in the absorption of the electromagnetic wave by different media, when the electromagnetic wave passes through cave and fracture zones, $\beta_{s}$ is much larger than that in the surrounding rock. Therefore, the field strength consumption in these areas is small, manifested as a negative anomaly. The distribution of $\beta_{s}$ in the electromagnetic wave image can help identify the cracks in the coal body, the stress of the coal body, and other information.

In addition, the resistivity of coal and rock mass is the dominant factor affecting electromagnetic wave attenuation. Moreover, the resistivity and $\beta_{s}$ are negatively correlated. That is, the higher the resistivity, the smaller $\beta_{s}$. The electrical resistivity of the coal seam can be influenced by the joints, metamorphism, water and gas contents, and stress status. The factors can also indirectly change $\beta_{s}$. Chen et al. [23] analyzed the change of coal resistivity during uniaxial compression. The results showed that the high-stress concentration closed the initial cracks and cavities inside the coal specimen and increased the density.

Nevertheless, the resistivity of the sample decreased with the increase of the load before the peak strength. When load approached and exceeded the compressive strength, the formation of new cracks led to an increase in resistivity. Therefore, when the stress concentration in the coal seam is higher, $\beta_{s}$ is larger. Instead, if the mining-induced stress in the coal seam is small or broken, $\beta_{s}$ decreases. Accordingly, the electromagnetic wave CT detection technology can be used to quantitatively analyze the coal's stress concentration and degree of damage.

3.2. Preparation before the Test. The operation of electromagnetic wave $\mathrm{CT}$ detection requires a transmitting hole and a receiving hole. The electromagnetic wave is generated by generators installed in the transmitting hole. The probes collect the electromagnetic wave in the receiving borehole after passing through the coal and rock mass between the two boreholes (Figure 5).

JW-6 underground high-frequency electromagnetic wave CT system (Figure 6) is used in this study, composed of the receiver, transmitter, antenna, mounting rod, and image postprocessing software.

The site was in Roadway A, No. 3107 working face. In different areas, the electromagnetic wave distribution in the coal seam was tested. Three sets of parallel cross-holes which are $110 \mathrm{~m}$ in front of the working face (station I), $150 \mathrm{~m}$ (station II), and $400 \mathrm{~m}$ behind the working face (station III) (Figure 7), were constructed in Roadway A. The label "R" stands for receiving drilling, and " $\mathrm{T}$ " stands for transmitting drilling. The coordinate system can be established by taking the boundary of No. 3106 working face as the origin and the inclination of the coal seam as the positive direction. The widths of the coal pillars and Roadway A are $30 \mathrm{~m}$ and $4 \mathrm{~m}$.

The field test results showed that the physical properties of the rock strata were affected by many factors, especially homogeneity, water content, and integrity. When the electromagnetic wave CT and borehole endoscopy are used to observe the surrounding rock undermining, it would be better to operate the test in a more homogeneous surrounding rock. Also, the inverse analysis of the observation results determines the key to the accuracy of the test. At the same time, repeated testing is also a high-precision method. There was no clear structure and water seepage in the coal seam where the stations were located. The length of the boreholes was $16 \mathrm{~m}$, and the spacing of the holes was $9 \mathrm{~m}$. The operating frequency of the electromagnetic wave CT detection system was set to $28 \mathrm{MHz}$. It adopted fixed-point receiving and completed the working measurement mode. The borehole endoscope was used to observe the development of cracks on the surface of the " $1 \mathrm{~T}$ " and " $1 \mathrm{R}$ " boreholes in station I to obtain the initial state of the surrounding rock of Roadway A. Due to the impact of mining, the boreholes in stations II and III were at the risk of collapse. In this study, borehole endoscopes were not used to observe these two stations.

3.3. Results. Due to the increase in mining-induced stress, the joints in the coal seam close, the resistivity reduces, and the degree of electromagnetic wave attenuation enhances. The electromagnetic wave attenuation coefficient is positively related to the mining-induced stress. The higher the pressure in the coal seam, the greater the electromagnetic wave attenuation coefficient. 


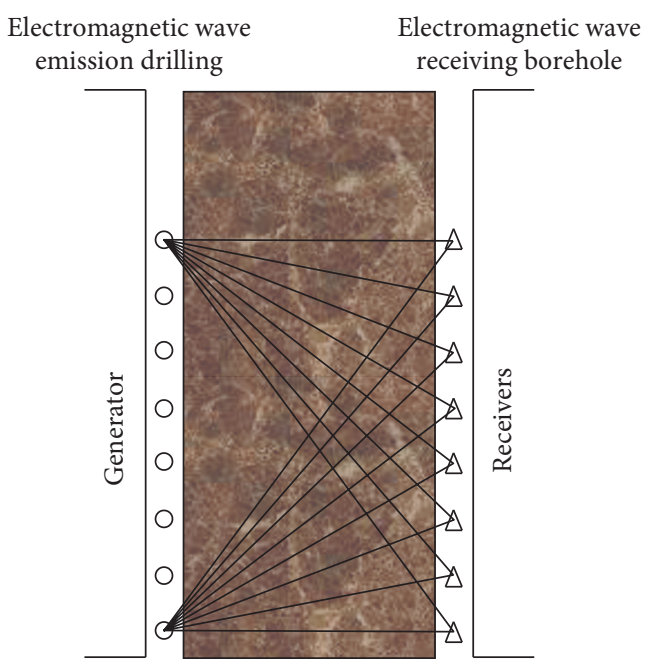

FIGURE 5: Layout of the cross-hole electromagnetic wave detection.

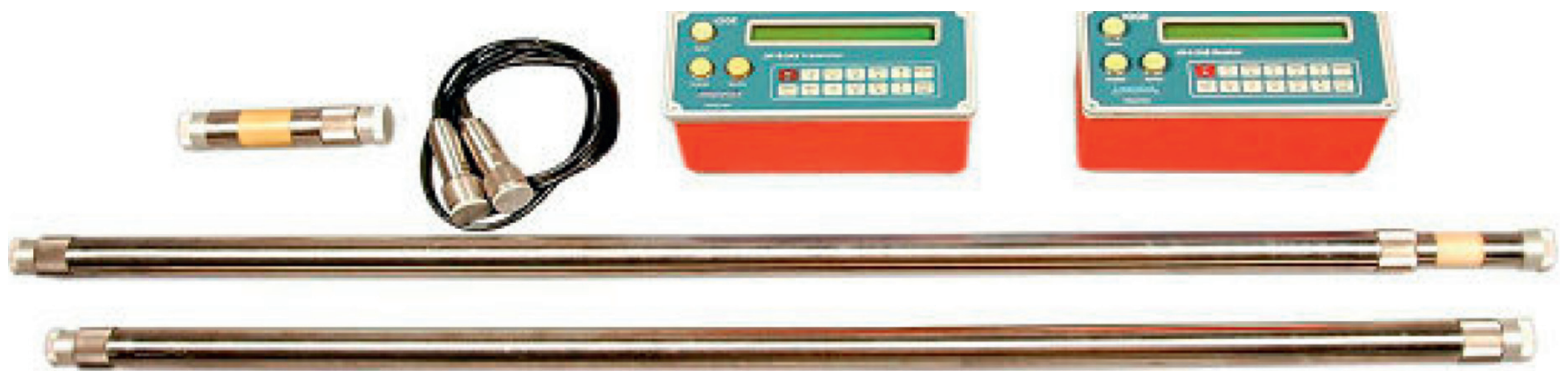

FIGURE 6: JW-6 underground high-frequency electromagnetic wave CT system.
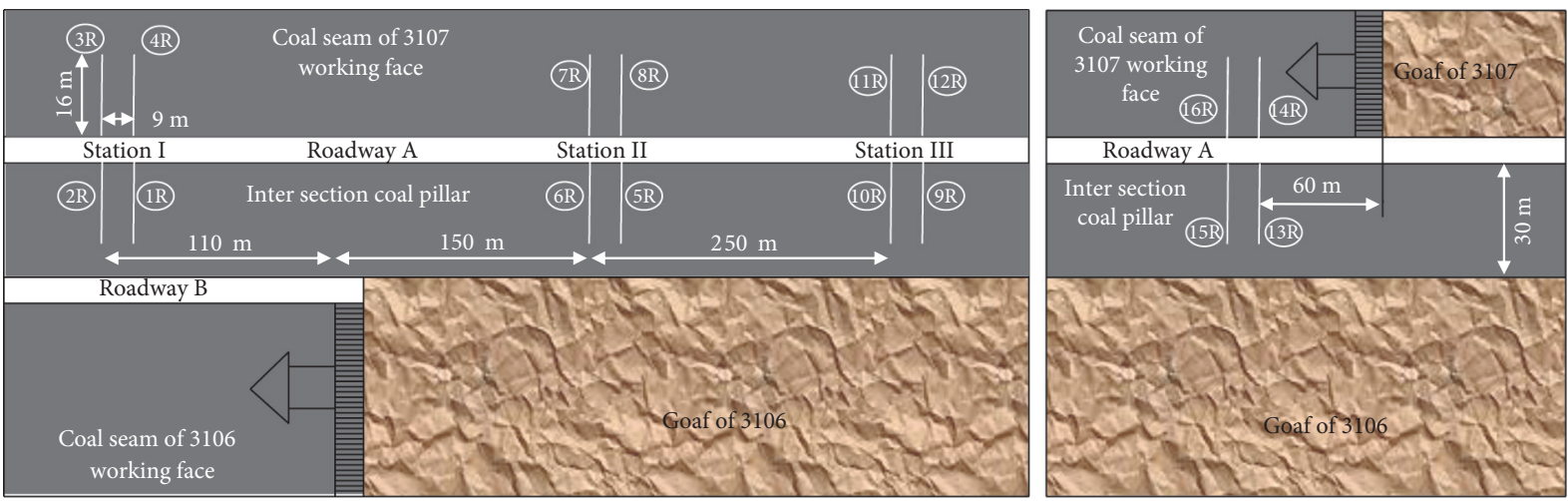

FIgURE 7: Layout of testing stations.

3.3.1. Station I. The surrounding rock where station I was located had not been affected by the mining of the working face, but the roadway excavation caused damage to the surrounding rock. It can be seen from the deterioration of the borehole surface (Figure 8 ) that, within the depth of $0-1 \mathrm{~m}$, the wall of the borehole is rough, and there are many cracks. It means that the coal seam is seriously damaged. In the depth of $2-4 \mathrm{~m}$, the wall of the borehole becomes much smoother. However, there are still some cracks developed in this area because of the influence of tunneling. When the depth exceeds $5 \mathrm{~m}$, the borehole wall is complete, and there are few cracks.
The change of $\beta_{s}$ in the coal seam where station $I$ is located is shown in Figure 9. Along the borehole, $\beta_{s}$ varies between 2.5 and $5 \mathrm{~dB} / \mathrm{m}$. In the range of $34-38 \mathrm{~m}$, that is, within $4 \mathrm{~m}$ of the roadway, the electromagnetic wave attenuation of the surrounding rock is lower than that in other areas. $\beta_{s}$ in some areas close to the borehole is also relatively small, indicating that the coal seam in this area has a higher degree of fracture. The results are consistent with the conclusions obtained by drilling endoscopy. Overall, $\beta_{s}$ of the unmined coal seam is small, and the stress concentration is low. 


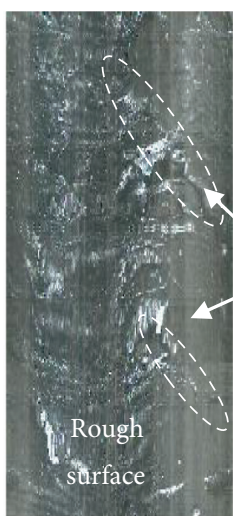

a $0 \sim 1 \mathrm{~m}$

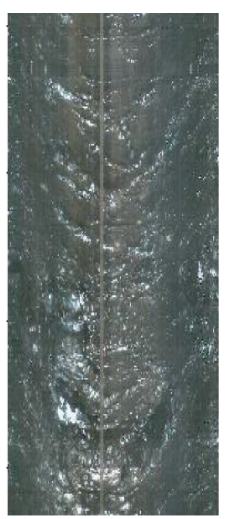

a $0 \sim 1 \mathrm{~m}$

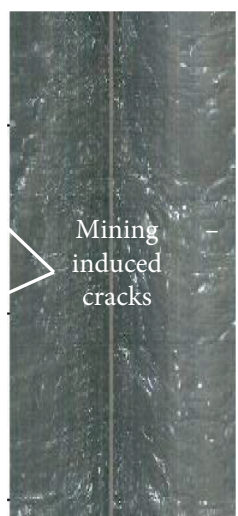

b $2 \sim 4 \mathrm{~m}$

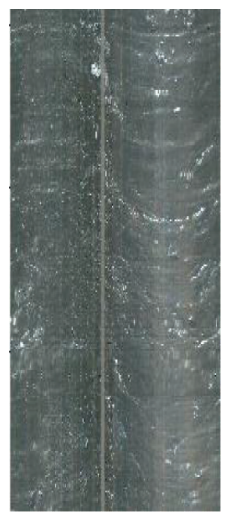

b $2 \sim 4 \mathrm{~m}$

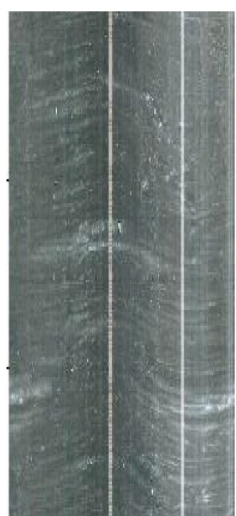

c $5 \sim 7 \mathrm{~m}$

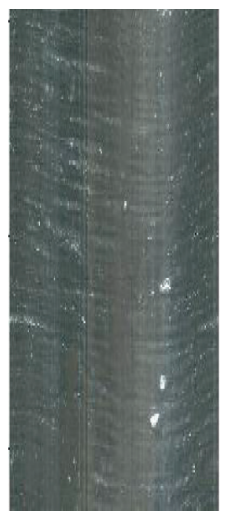

c $5 \sim 7 \mathrm{~m}$

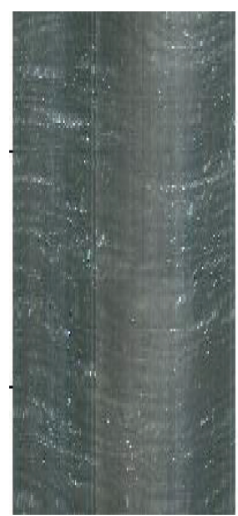

d $8 \sim 10 \mathrm{~m}$

(1) $1 \mathrm{~T}$

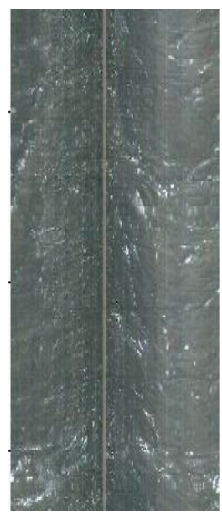

$\mathrm{d} 8 \sim 10 \mathrm{~m}$

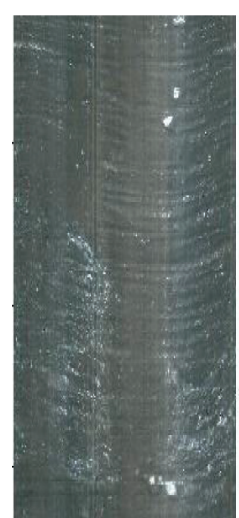

e $12 \sim 14 \mathrm{~m}$

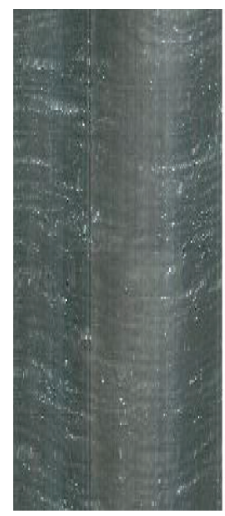

e $12 \sim 14 \mathrm{~m}$

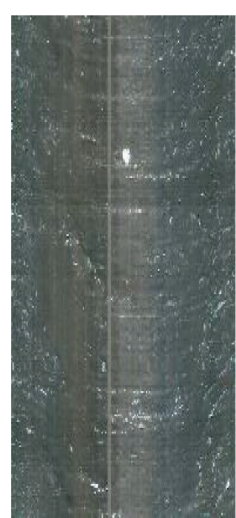

f $14 \sim 16 \mathrm{~m}$

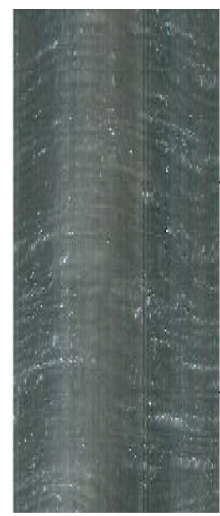

f $14 \sim 16 \mathrm{~m}$

(2) $1 \mathrm{R}$

FIgURE 8: Images of the surface of the borehole in station I.

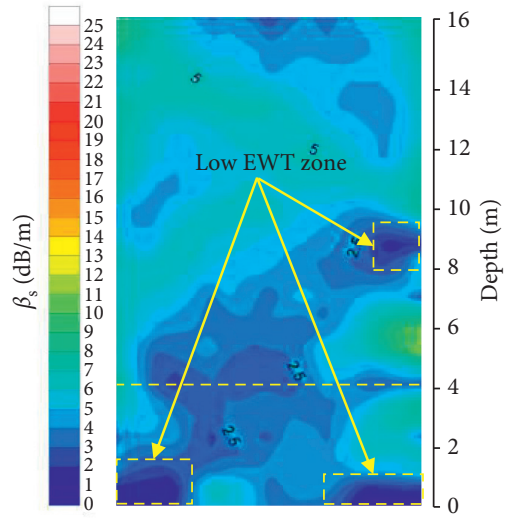

FIgURE 9: Electromagnetic CT image of station I.

3.3.2. Station II. For station II and station III, the crossholes in the coal seam of No. 3107 working face were located in the external stress field, and the boreholes in the intersection coal pillar were within the internal stress field. $\beta_{s}$ in the area where the two stations are located is significantly increased. The electromagnetic wave image obtained through the No. 2 cross-hole (Figure 10(a)) shows that $\beta_{s}$ in this area is generally less than $5 \mathrm{~dB} / \mathrm{m}$ in the range of 34-48 m. Among them, the low EWT zone in the coal seam in the shallow depth area near the roadway is broken due to the impact of excavation. In the range of $38-46 \mathrm{~m}, \beta_{s}$ varies between 5 and $10 \mathrm{~dB} / \mathrm{m}$; within $46-50 \mathrm{~m}$, the scope of $\beta_{s}$ is $7-22 \mathrm{~dB} / \mathrm{m}$, and $\beta_{s}$ reaches its maximum value at $48 \mathrm{~m}$. In summary, in the external stress field, as the depth of the coal seam increases, $\beta_{s}$ in the coal seam increases rapidly, which means that the concentration degree of mining-induced stress rises. The electromagnetic wave CT image obtained by the No. 3 cross-hole in the internal stress field is shown in Figure 10 (b). The range of $14-20 \mathrm{~m}$ is the high EWT zone, and the peak value is about $18 \mathrm{~dB} / \mathrm{m}$, which is lower than the result of the external stress field. In the range of $22-30 \mathrm{~m}$, there is an apparent low EWT zone, and the variation range of $\beta_{s}$ is $5-12 \mathrm{~dB} / \mathrm{m}$.

3.3.3. Station III. Station III is farther from the work surface than station II. In this area, the movement and deformation of the overlying strata reached a stable state. The features of electromagnetic wave CT images obtained by No. 4 and No. 5 cross-holes in station III are similar to those of station II. There is a high-stress concentration area in the external stress field in the range of $46-50 \mathrm{~m}$, and the maximum value of $\beta_{s}$ is $14 \mathrm{~dB} / \mathrm{m}$ (Figure $10(\mathrm{c})$ ). $14-18 \mathrm{~m}$ is a high-stress concentration area in the internal stress field, and the maximum value of $\beta_{s}$ is $18 \mathrm{~dB} / \mathrm{m}$ (Figure 10(d)). 


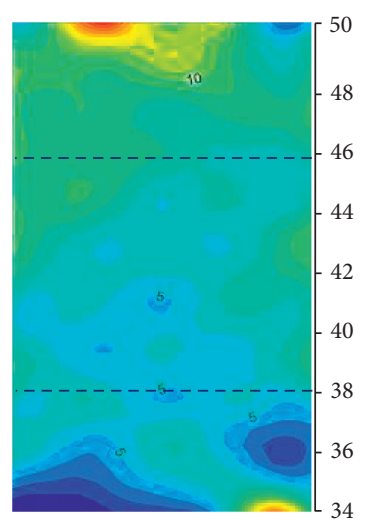

(a)

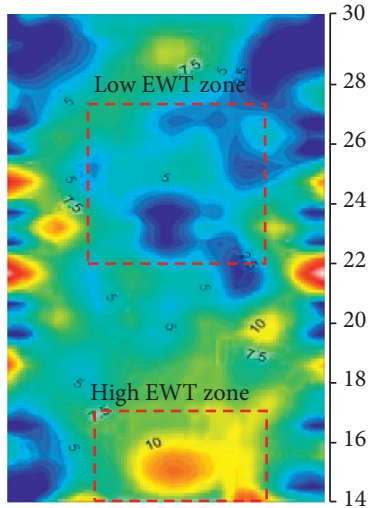

(b)

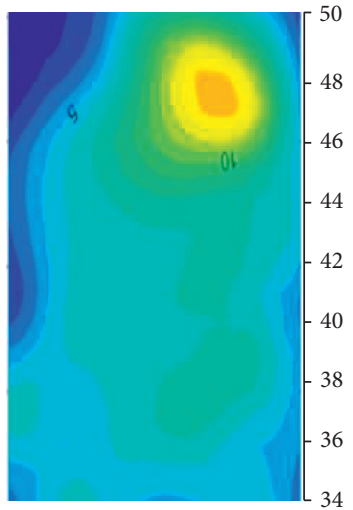

(c)

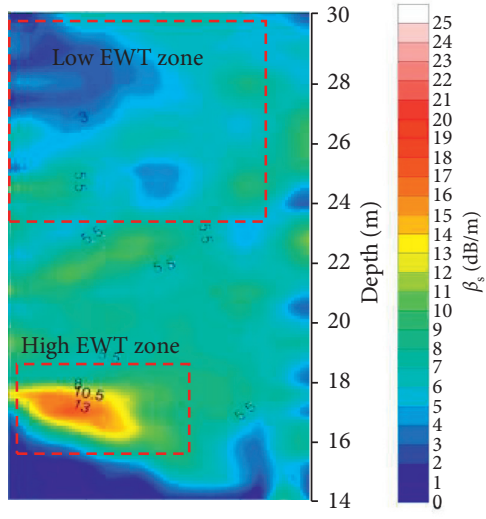

(d)

Figure 10: Electromagnetic CT image of station II and station III. (a) No. 2 cross-hole. (b) No. 3 cross-hole. (c) No. 4 cross-hole. (d) No. 5 cross-hole.

Combining the observation results of electromagnetic wave CT and the calculation results of the MSMS model, it can be seen that both methods have confirmed the existence of internal and external stress fields. For the Lu-Zi-Gou coal mine, the maximum mining-induced stresses of the internal and external stress fields are located at $14-16 \mathrm{~m}$ and $44-50 \mathrm{~m}$ in the lateral direction of the stope, respectively.

\section{Conclusion}

This research is aimed to obtain the distribution of the mining-induced stress in the extrathick coal seam. The elastoplastic analysis, borehole endoscopy, and electromagnetic wave CT detection were utilized. The main conclusions obtained in this study are as follows:

(1) The mining-induced stress in the side coal seam of the stope is formed by multisources which are the broken roof block in the caving zone, the side unbroken rock strata in the goaf, and the rock stratum in the bending zone. Accordingly, the multiforce superposition mining-induced stress model was established, and the calculation formula for mininginduced stress in the coal seam was derived.

(2) Based on the mining and geological situation of the Lu-Zi-Gou coal mine, the distribution of the mininginduced stress in the extrathick coal seam is calculated. The results show that the mining-induced stress has formed internal and external stress fields in the coal seam beside the goaf. As the horizontal burial depth increases in the two fields, the stress in both fields increases first and then decreases. The maximum value of mining-induced stress and its position in the internal and external stress fields are $23 \mathrm{MPa}, 16 \mathrm{~m}$, and $34 \mathrm{MPa}, 44 \mathrm{~m}$, respectively.

(3) Electromagnetic wave CT detection technology and borehole endoscopy are adopted to conduct on-site tests. The value of $\beta_{s}$ of the unaffected coal seam is $2.5-5 \mathrm{~dB} / \mathrm{m}$. Due to the mining influenced, $\beta_{s}$ increases significantly. In the internal and external

stress fields, the maximum value of $\beta_{s}$ is about $18-22 \mathrm{~dB} / \mathrm{m}$. The calculated results of the MSMS model are in good agreement with the field data received by electromagnetic wave $\mathrm{CT}$.

\section{Nomenclature}

$H:$

$h:$

$h_{i}:$

$L:$

$\alpha, \beta$ :
Burial depth of the coal seam Mining height of the working face Thickness of each rock stratum Length of the working face Angle between the moving and breaking boundary of the roof and the horizontal direction

$H_{1}, H_{2}$, and Height of the caved, fracture, and bending $\mathrm{H}_{3}$ : zones, respectively

$P_{i}$ : $\quad$ Load applied on the unbroken rock strata by $\Delta q_{i}: \quad$ the broken roof in the goaf in the caved zone

rock strata

$F_{i}$ : Load generated by the bending zone

$\sigma: \quad$ Mining-induced stress

$s \gamma: \quad$ Weight stress of the overlying strata

$\sigma_{1}$ : $\quad$ Additional stress generated by the broken roof in the goaf

$\sigma_{2}$ : $\quad$ Stress produced by the bending zone

$\gamma$ : Unit weight of rock strata

$\beta_{s}$ : $\quad$ Electromagnetic wave attenuation coefficient

$K: \quad$ Resistivity, $\Omega / \mathrm{m}$

$\omega: \quad$ Angular frequency, $1 / \mathrm{s}$

$\mu: \quad$ Magnetic permeability, $\mathrm{H} / \mathrm{m}$

$\varepsilon: \quad$ Dielectric constant of the medium, $\mathrm{F} / \mathrm{m}$.

\section{Data Availability}

The data are available on request due to privacy/ethical restrictions.

\section{Conflicts of Interest}

The authors declare that they have no conflicts of interest. 


\section{Acknowledgments}

Support for this work was provided by the Natural Science Foundation of Hebei Province (E2020402042, E2020402041, and E2021402061), the Open Fund Project of State Key Laboratory (SKLCRKF20-04), and the National Natural Science Foundation of China (51804093).

\section{References}

[1] J. F. Ju, J. L. Xu, W. B. Zhu, W. Qing-xiong, and H. Xian-jie, "Strata behavior of fully-mechanized face with $7.0 \mathrm{~m}$ height support," Journal of Mining \& Safety Engineering, vol. 3, pp. 344-351, 2012.

[2] J. H. Wang, "Key technology for fully-mechanized top coal caving with large mining height in extra-thick coal seam," Journal of China Coal Society, vol. 38, no. 12, pp. 2089-2098, 2013.

[3] B. Wang and Q. Wang, "Non-repeated advance support technology: a fully mechanized caving face in extra thick coal seam of North China," Arabian Journal of Geosciences, vol. 14, no. 19, pp. 1-13, 2021

[4] J. Chai, W. Lei, W. Du et al., "Experimental study on distributed optical fiber sensing monitoring for ground surface deformation in extra-thick coal seam mining under ultrathick conglomerate," Optical Fiber Technology, vol. 53, Article ID 102006, 2019.

[5] M. E. Yetkin, A. T. Arslan, M. K. Özfirat, B. Kahraman, and H. Yenice, "Numerical modelling of stress-strain analysis in underground thick coal mining," International Journal of Engineering Research and Technology, vol. 7, no. 4, pp. 199-204, 2018.

[6] V. Klishin, "Innovative technologies for thick coal seam mining on the basis of powered roof support with controlled coal discharge," IOP Conference Series: Earth and Environmental Science, vol. 262, no. 1, Article ID 012027, 2019.

[7] R. Singh, "Staggered development of a thick coal seam for full height working in a single lift by the blasting gallery method," International Journal of Rock Mechanics and Mining Sciences, vol. 41, no. 5, pp. 745-759, 2004.

[8] R. Kumar, A. K. Singh, A. K. Mishra, and R. Singh, "Underground mining of thick coal seams," International Journal of Mining Science and Technology, vol. 25, no. 6, pp. 885-896, 2015.

[9] Z. Q. Song, J. Hao, J. Q. Tang, and J. Liu, “An overview of connotation and development of practical ground pressure control theory," Journal of Shandong University of Science and Technology, vol. 3, no. 1, pp. 1-15, 2019.

[10] H. Agrawal, S. K. Singh, and A. P. Singh, "Thick coal seam mining methods: challenges and opportunities," Indian Mining \& Engineering Journal, vol. 55, no. 3, pp. 16-21, 2016.

[11] Q. Guangpeng, C. Jing, W. Chao, W. Shuo, and Z. Minghua, "Characteristics of stratum structure and fracture evolution in stratified mining of shallow buried high-gas-thick coal seam by similarity simulation," Geofluids, vol. 2021, Article ID 5555451, 2021.

[12] R. Kumar, A. K. Mishra, A. K. Singh, A. K. Singh, S. Ram, and R. Singh, "Depillaring of total thickness of a thick coal seam in single lift using cable bolts: a case study," International Journal of Mining Science and Technology, vol. 26, no. 2, pp. 223-233, 2016.

[13] P. K. Mandal, R. Singh, J. Maiti, A. K. Singh, R. Kumar, and A. Sinha, "Underpinning-based simultaneous extraction of contiguous sections of a thick coal seam under weak and laminated parting," International Journal of Rock Mechanics and Mining Sciences, vol. 45, no. 1, pp. 11-28, 2008.

[14] T. He, Y. X. Wei, X. L. Zhang, and M. T. Sun, "Internal and external stress fields formation mechanism and loading transmitting of fully mechanized top coal caving with extra thick coal seam," Coal Mining technology, vol. 24, no. 1, pp. 98-103, 2019.

[15] Y. Zhao, Y. Yang, X. Li, Z. Wang, and M. T. Sun, "Overlying strata movement and abutment pressure evolution process of fully mechanized top coal caving mining in extra thick coal seam," Geofluids, vol. 2021, Article ID 7839888, 2021.

[16] C. Zhu, J. Zhang, M. Li, Z. He, Y. Wang, and Y. Lan, "Effect mechanism of strata breakage evolution on stope deformation in extra-thick coal seams," Alexandria Engineering Journal, vol. 61, 2021.

[17] R. J. Greenfield and S. T. Wu, "Electromagnetic wave propagation in disrupted coal seams," Geophysics, vol. 56, no. 10, pp. 1571-1577, 1991.

[18] C. G. Kim, "An analysis of doses and images of mobile CT of high-energy electromagnetic wave area," Journal of Magnetics, vol. 25, no. 4, pp. 644-648, 2020.

[19] P. Hatherly, "Overview on the application of geophysics in coal mining," International Journal of Coal Geology, vol. 114, pp. 74-84, 2013.

[20] O. Yildırım, "Scattering of electromagnetic waves and prediction remarks regarding mining," in Proceedings of the Int Scientific Conference Sgem, vol. 14, Sofia,Bulgaria, 2010.

[21] C. F. Guo, X. Wu, Z. Yang, Y. D. Chen, L. Z. Ma, and Z. Y. Ma, "Research on intelligent inversion method of electromagnetic wave CT detection within working face under the constraint of multi-source information fusion," Journal of China Coal Society, vol. 46, no. 11, pp. 1-13, 2021.

[22] X. Wu, G. Li, F. Luo, and S. Duan, "A study on the distribution and evolution of mining induced stress under the condition of multiple mining," Geotechnical \& Geological Engineering, vol. 39, no. 2, pp. 1637-1648, 2021.

[23] P. Chen, Y. M. Jia, E. Y. Wang, and Y.-F. Zhu, "Experimental study on resistivity variation regularities of loading coal," Journal of Coal Society, vol. 11, pp. 47-49, 2008. 